\title{
COMPARAÇÃO ENTRE OS VALORES DE BRILHO OBTIDOS EM ROCHA ORNAMENTAL SUBMETIDA AO PROCESSO DE POLIMENTO COM DIFERENTES RESINAS
}

\author{
COMPARISON BETWEEN THE GLOSS VALUES OBTAINED IN DIMENSION STONE \\ SUBMITTED TO THE POLISHING PROCESS WITH DIFFERENT RESINS
}

\author{
Bernardo Bernardi MARTINS, Leonardo Luiz Lyrio da SILVEIRA \\ Centro de Tecnologia Mineral. Av. Pedro Calmon, 900 - Cidade Universitária da Universidade Federal do Rio de Janeiro, Rio de \\ Janeiro - RJ. E-mail: bernardomartins_12@hotmail.com; leolysil@cetem.gov.br
}

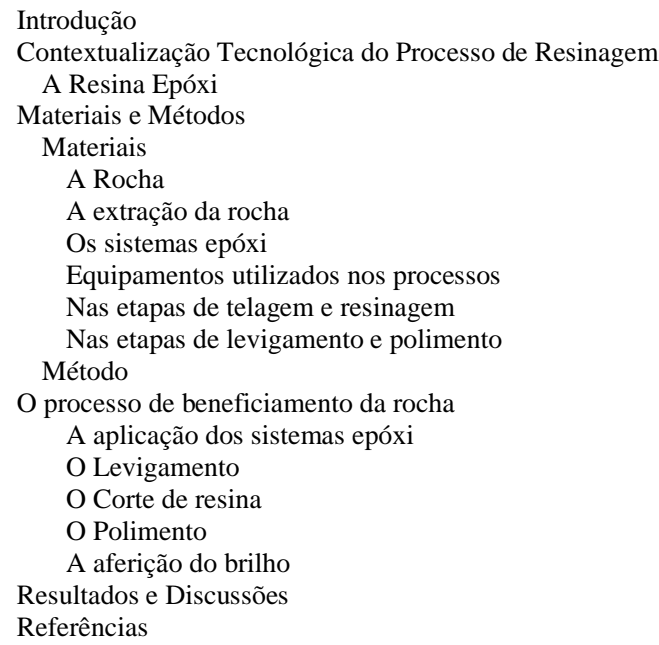

\begin{abstract}
RESUMO - O brilho de uma rocha ornamental após o polimento é a principal característica analisada em relação a qualidade de produção, fator que pode ser decisivo durante a comercialização do mesmo. De forma empírica se diz que a resina é parte influenciadora na qualidade do brilho após o polimento da rocha. Para tanto, esse artigo demonstra, através do experimento realizado em uma indústria, por meio do polimento de chapas retiradas a partir de um veio de quartzo em meio a um corpo pegmatítico, o quanto o brilho aferido obteve uma diferença entre tais superfícies que receberam diferentes aplicações de sistemas epóxi, de forma a evidenciar quais as características desses sistemas que provocaram a influência direta no resultado do brilho. Os resultados mostraram que existe uma íntima relação entre o sistema adotado e os resultados de brilho medidos. Na rocha estudada, o sistema que melhor gerou brilho, foi o IV, apresentando valores bem superiores a outros também testados. Aspectos relacionados a preço dos insumos e tempo de produção devem ser considerados quando da escolha de qual sistema deverá ser adotado. Essa pesquisa é um passo importante para a mitigação do empirismo que permeia o setor de rochas ornamentais e visa um maior controle do processo produtivo e um aumento da qualidade das rochas ornamentais brasileiras.
\end{abstract}

Palavras-Chave: Rocha ornamental, Brilho, Sistema Epóxi e Polimento.

ABSTRACT - The brightness of a dimension stone after polishing is the main characteristic analyzed in relation to the quality of production, a factor that can be decisive during its commercialization. Empirically, it is said that resin is an influential part of the quality of the gloss after polishing the stone. For this purpose, this article demonstrates, through an experiment carried out in an industry, by polishing slabs removed from a quartz vein into a pegmatitic body, a difference in the measured brightness in surfaces that received different epoxy systems, in order to demonstrate what the characteristics of these systems that caused the direct influence on the brightness result. The results showed that there is an intimate relationship between the adopted system and the measured brightness results. In this study, the best system was the IV, presenting values much higher than the others. Aspects related to the price of the inputs and production time must be considered when choosing which system should be adopted. This research is an important step towards a reduction in the empiricism that permeates the dimension stones sector and aims at better control of the production process and an increase in the quality of Brazilian dimension stones.

Keywords: Dimension Stones, Gloss, Epoxy System, Polishing.

\section{INTRODUÇÃO}

Observa-se que a indústria do setor de rochas ornamentais está em uma constante transformação tecnológica, na qual essa evolução pode ser notada pela capacidade e velocidade de produção, obtidas através de novas tecnologias referentes às linhas de implementos e na melhoria da qualidade dos insumos destinados à produção. Sendo assim, o resultado na indústria de beneficiamento de rochas ornamentais é traduzido em possíveis aumentos de volume de 
produção e na melhoria da qualidade final do produto.

Após realizar o balanço das exportações de rochas ornamentais em 2019, o mercado respondeu com uma variação positiva de 1,97\% em valores, quando comparado com o ano de 2018, atingindo uma marca superior a US\$ 1 bilhão.

Porém, nota-se uma queda no volume de materiais exportados também em comparação ao ano anterior, na qual houve uma variação negativa de $1,94 \%$.

Em meio as exportações de rochas ornamentais registradas no $1^{\circ}$ semestre de 2019, os Estados Unidos se destacam com a maior fatia desses valores, totalizando um montante de U\$ 306,6 milhões correspondendo a $62,5 \%$ do total do faturamento.

Quando observado os países produtores, a China se destaca dentre os demais por ter o maior e um dos mais tecnológicos parques industriais, além de ser a maior importadora de rochas ornamentais do mundo. Em meio a essas grandes potências econômicas já citadas, o Brasil vem disponibilizando nesse mercado, materiais cada vez mais raros e de alto valor econômico, o que faz dessa atividade um triunfo para algumas macro e microrregiões, na qual pode-se citar estados que tem o setor de rochas ornamentais como uma fonte importante na geração de receita, como ilustrado na figura 1 . O estado do Espirito Santo é o principal produtor e exportador desse bem mineral, movimentando US\$ 564,1 milhões no primeiro semestre de 2019, ficando à frente de estados como Minas Gerais e Ceará (Abirochas, 2019).

Apesar do estado do Espírito Santo ser o principal estado exportador, observa-se na tabela 1, que o mesmo não tem tanta importância, quando analisado o consumo do mercado interno, sendo o estado de São Paulo o maior consumidor de rochas ornamentais do País, consumindo mais que o dobro que os demais estados da região sudeste.

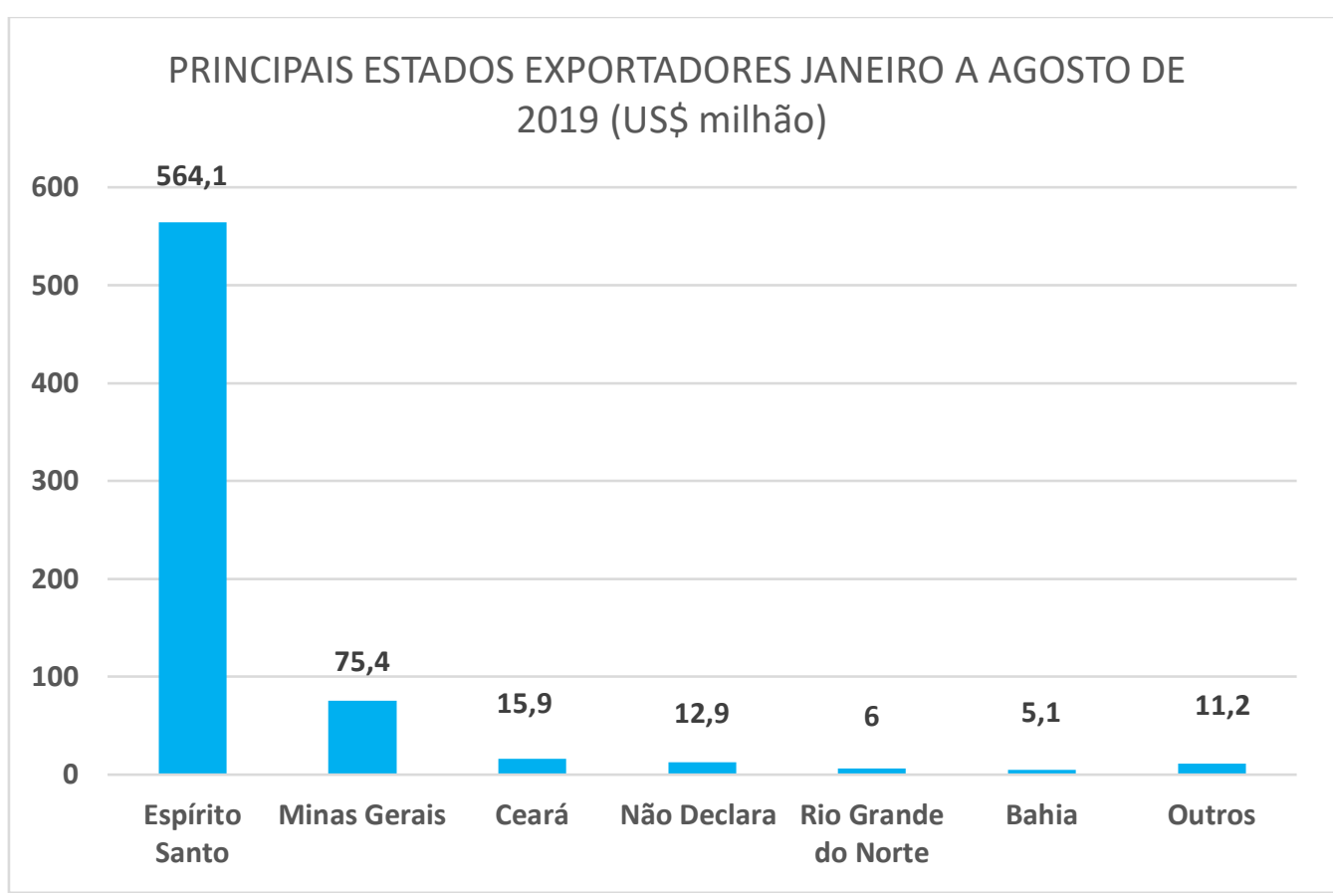

Figura 1 - Principais estados exportadores período de janeiro a agosto de 2019.

Tabela 1 - Consumo de rochas ornamentais mercado interno - São Paulo se destaca como maior consumidor de rochas ornamentais do Brasil.

\begin{tabular}{c|c|c}
\hline Distribuição do consumo interno aparente de rochas ornamentais no Brasil por estados e regiões - 2018 \\
\hline UF / Região & Consumo (106 $\mathbf{~ m}^{\mathbf{2}}$ equivalentes) & Participação (\%) \\
\hline São Paulo & 30,5 & 45 \\
\hline Espírito Santo, Rio de Janeiro, Minas Gerais & 14,9 & 22 \\
\hline Região Sul & 9,5 & 14 \\
\hline Regiões Nordeste, Norte, Centro Oeste & 12,9 & 19 \\
\hline Total Estimado & 67,8 & 100
\end{tabular}

Fonte: Adaptado de Abirochas (2019b). *Chapas com 2 cm de espessura equivalentes. 
Com o avanço e a disponibilidade da tecnologia para o setor produtivo de rochas ornamentais, as dificuldades para a produção foram minimizadas, o que resultou em um aumento da concorrência, quando as empresas passaram a adotar estratégias distintas para o sucesso ou a sobrevivência ne setor econômico.

O baixo custo de produção é uma estratégia muito utilizada pelas empresas, onde essas optam ou por diminuir o número de processos utilizados na escala de produção ou por trabalhar com matéria prima e insumos de qualidade inferiores, tendo como consequência a produção de um material de menor qualidade, se comparado àquelas empresas que seguem todos os processos produtivos e que empregam insumos de qualidade superior.

No entanto, essas indústrias que empregam insumos de melhor qualidade e seguem os processos necessários para uma boa qualidade do produto, devem ter em seu portfólio materiais únicos e de alto valor agregado, pois com o incremento da valoração de uma chapa de rocha ornamental, teoricamente há um aumento também nos custos de produção.

Com um aumento das receitas das exportações em 2019 e, uma diminuição do volume exportado, a tendência é que as empresas exportadoras adotem a estratégia de conduzir seus esforços em função desses materiais que estão obtendo um crescente preço médio de venda.

Porém, mercados internacionais que consomem rochas de alto valor agregado, buscam qualidade no produto final, criando assim a necessidade nas indústrias beneficiadoras de manter o alto controle de qualidade nos processos e nos insumos, desde a extração da rocha até o término do beneficiamento e um dos principais fatores a serem avaliados na qualidade final do produto, é a qualidade do brilho que o material obtém após o processo de polimento. $\mathrm{O}$ tipo de resina a ser aplicada na rocha é um dos fatores de maior influência nos valores finais de brilho após esta etapa industrial.

Sendo assim, esse artigo tem o objetivo de demonstrar o quanto um insumo, nesse caso a resina, pode alterar a qualidade final do produto, que foi mensurada através da medição do brilho após o processo de polimento de uma rocha ornamental submetida a diferentes tipos de sistemas epóxi.

\section{CONTEXTUALIZAÇÃO TECNOLÓGICA DO PROCESSO DE RESINAGEM}

\section{A Resina Epóxi}

As resinas de base epoxídica começaram a ser utilizada no setor produtivo de rochas ornamentais brasileiro a partir do momento em que se observou um acabamento ineficiente evidenciado pela ocorrência de poros, fissuras e microfissuras após o polimento das chapas.

A utilização da resina epóxi se deu com o intuito de realizar o preenchimento destas irregularidades presentes nas superfícies polidas. Ficou demostrado que, a partir da utilização de tais resinas, houve um produto final sensivelmente superior, refletido em uma superfície de chapa mais uniforme, sem a presença de características indesejáveis, na qual os valores de brilho foram aumentados.

Goulding (2003) diz que as resinas epóxi comercializadas são produzidas através do processo de polimerização por condensação da epicloridrina e o bisfenol A (figura 2), conhecida também como resina DGEBA (diglicedil-éter de bisfenol A).

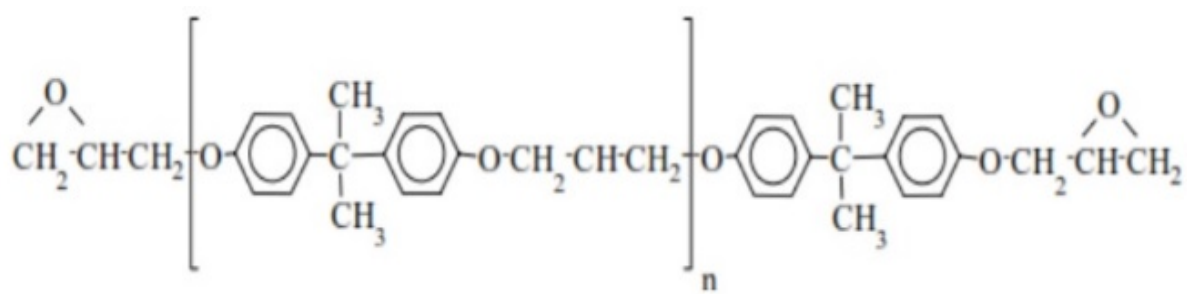

Figura 2 - Estrutura geral de uma resina DGBEA, em que (n) corresponde ao grau de polimerização. Fonte: Goulding (2003).

Cabe salientar que a resina é apenas um componente, o outro componente que reage com a resina para obter a catálise da mesma, é conhecido como endurecedor ou catalisador, na qual esse é responsável por reagir com as resinas que possuem grupos funcionais reativos ao mesmo, assim formando o chamado sistema epóxi ou o polímero termorrígido.

Quando a resina e o endurecedor são homogeneizados em proporções indicadas pelo fabricante, tem o início de uma reação que mediante a presença de calor propicia um processo 
de reticulação interna, conhecido como cura ou catálise, resultando em um sistema altamente entrelaçado proporcionando uma elevada resistência mecânica e química.

Com os processos produtivos cada vez mais dinâmicos na indústria, os gestores observaram a necessidade de aperfeiçoar esse processo produtivo, pois o intervalo de tempo entre a resinagem e o momento ideal para o polimento estava gerando um gargalo de produção, assim resultando em dificuldade para o atendimento às demandas de entrega de chapas polidos. Diante disso, o setor de rochas ornamentais começou a adaptar e criar equipamentos para otimizar a produção.

Em um primeiro momento começou a ser utilizado o maçarico lança chamas, também conhecido no setor como "pela porco", ilustrado na figura 3. O equipamento tem a função de aquecer as superfícies das chapas para eliminar a umidade presente nas mesmas, bem como dilatar as micro descontinuidades presentes nos materiais (microfissuras, planos de clivagem, e.g.), auxiliando assim na maior penetração do sistema epóxi na rocha. O que se observou nessa técnica foi uma aceleração no tempo de gel da resina, e no intervalo de tempo entre o processo de resinagem e polimento, pois uma vez que o material foi aquecido, a temperatura de aplicação da mistura resina e endurente vai ser maior, iniciando assim mais cedo o processo de catálise.

A partir dessa constatação, equipamentos com maior aporte tecnológico foram criados. Pode-se citar o forno de passagem, como observado na figura 4, sendo um dispositivo na qual as chapas são colocadas em um forno, e são aquecidas através de resistência elétrica ou de chamas com auxílio de gás GLP.

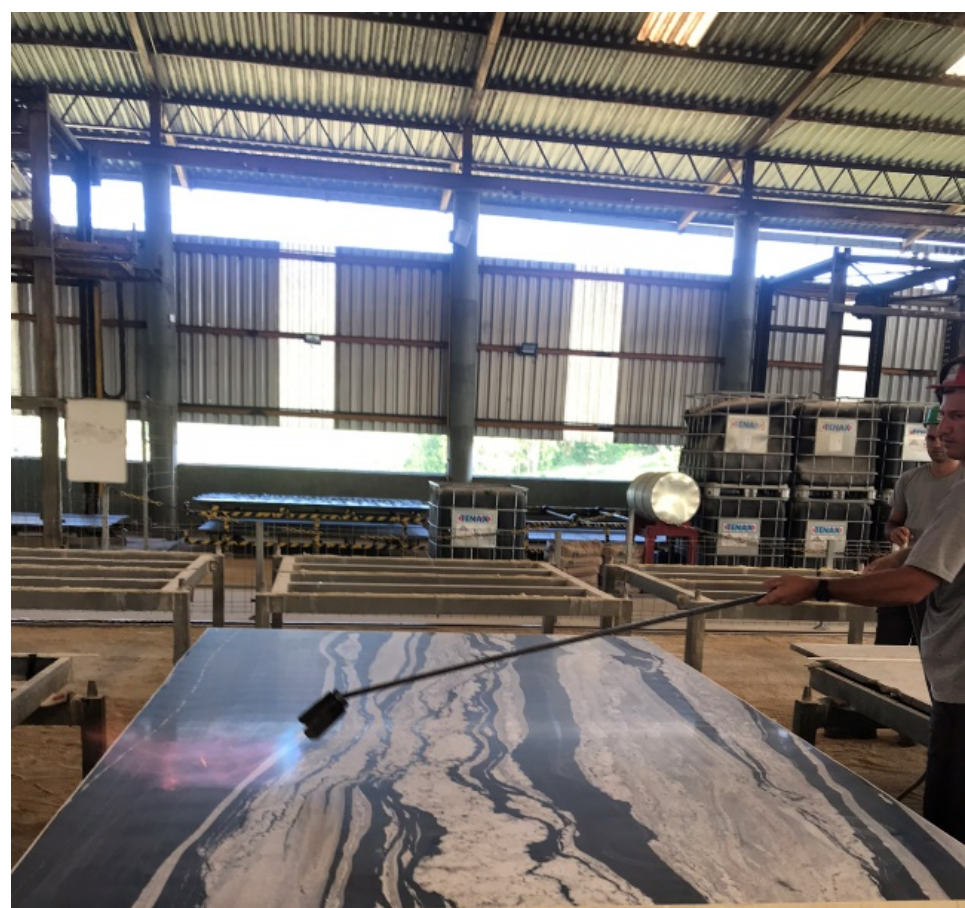

Figura 3 - Processo de aquecimento da superfície da chapa com a utilização do lança chamas "pela porco".

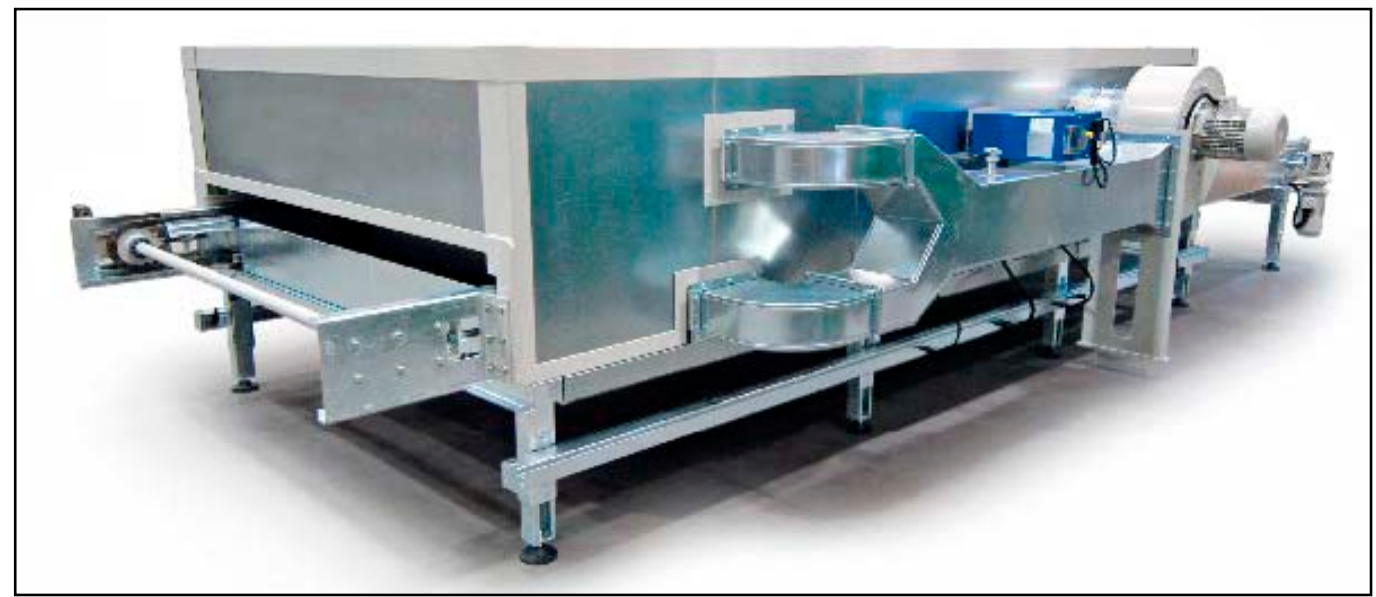

Figura 4 - Imagem ilustrativa de um forno de passagem. 
Com a utilização do forno de passagem foi constatado uma redução ainda maior do tempo entre a resinagem e o polimento. Porém, a indústria ainda demandava um equipamento que acelerasse ainda mais o tempo de produção na resinagem com uma menor dependência de mão de obra especializada, e que permitisse a realização de um processo com qualidade superior. Assim, foram desenvolvidas as linhas automáticas de resinagem, as quais foram providas de dois fornos, tendo o primeiro a função de realizar o aquecimento da rocha antes do momento da aplicação da mistura (resina + endurecedor) e o segundo que acelera a catálise da chapa já com o sistema epóxi aplicado sobre ela, o que diminuiu consideravelmente o tempo de espera para o processo de polimento. $\mathrm{Na}$ figura 5 é possível visualizar o segundo forno da linha automática.

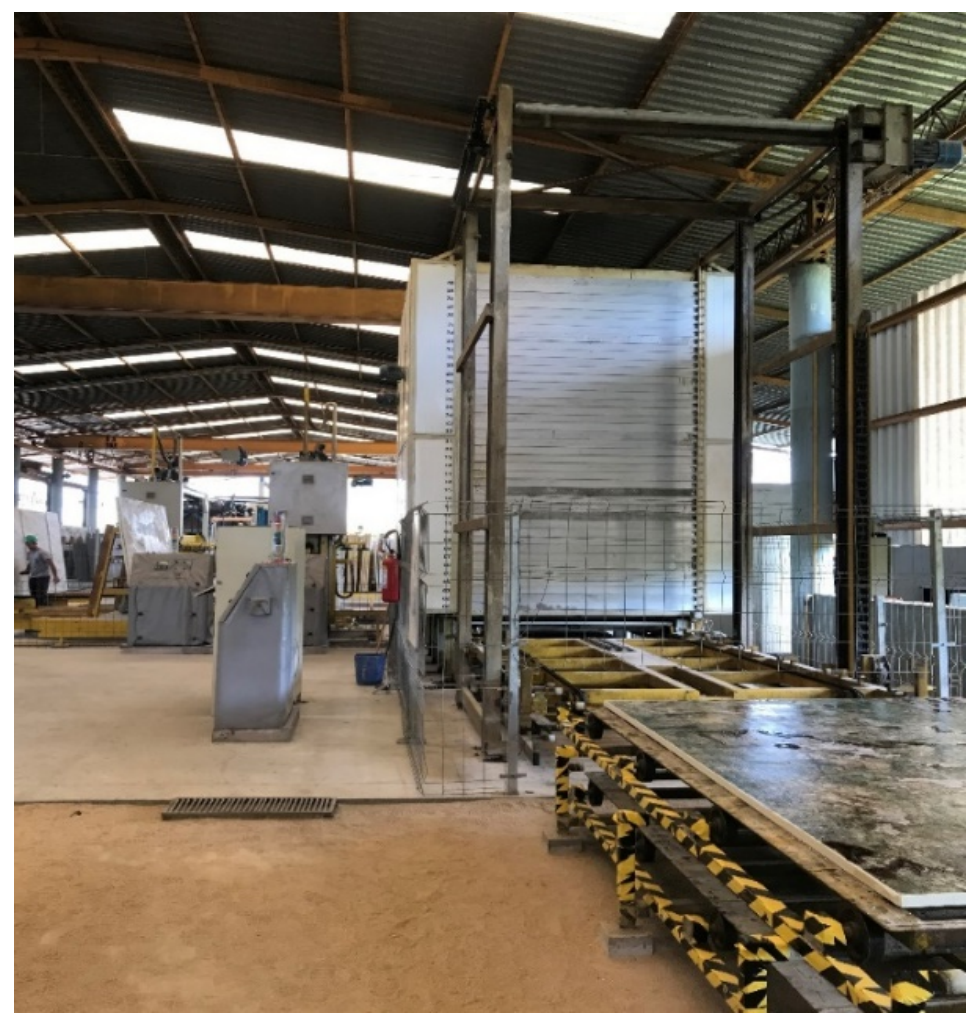

Figura 5 - Vista do forno de catálise da linha automática de resina automática (estrutura metálica em formato vertical).

A mais recente inovação tecnológica para o processo de resinagem foi a fabricação de equipamentos utilizados para aplicação do sistema epóxi sobre as chapas de rochas ornamentais, na qual os equipamentos mais avançados possuem um robô aplicador, onde a resina é aplicada aquecida, e distribuída sobre a superfície da chapa por equipamentos específicos, sem que seja necessária a presença de mão de obra humana. Cabe salientar tais equipamentos, como o forno de passagem, a linha automática de resinagem, o aquecedor de resina e endurente, possuem um controle de temperatura que pode ser alterado pelos operadores de acordo com a mistura a ser utilizada e a rocha a ser processada.

No setor de rochas ornamentais, quando se analisa qual melhor sistema epóxi a ser utilizado para beneficiamento da rocha, características como viscosidade, tempos de catálise e de gel, além do período pré-polimento, são características importantes para a tomada de decisão de acordo com as propriedades da rocha a ser trabalhada e o tempo necessário para produção.

A viscosidade é uma propriedade relevante a ser considerada, pois quando se tem um produto de baixa viscosidade, a facilidade de o mesmo penetrar nos poros e nas fissuras da rocha é maior em comparação a um sistema de maior viscosidade, pois quanto mais o sistema epóxi penetrar na rocha, propriedades mecânicas da mesma serão elevadas, visto que mais profundo irá ser o preenchimento dos poros e das fissura, garantindo assim um preenchimento maior dos vazios presentes na rocha. Por outro lado, quando se utiliza uma resina com viscosidade maior, há menos alteração cromática na superfície da rocha, ou seja, quanto menos o produto penetrar na rocha, menor vai ser alteração da tonalidade original do material.

Outro fator a ser levado em consideração para estabelecer qual sistema utilizar em uma rocha, é o tempo de catálise, no qual é determinado pelo 
endurecedor, existindo aqueles que aceleram mais o tempo de cura do sistema e outros que exercem a função contrária.

Não menos importante, o tempo de gel é um terceiro aspecto observado como característica de um sistema epoxídico para indicação de utilização em uma rocha. Esta variável é definida pelo tempo em que o sistema inicia a perder sua característica de fluidez, ou seja, é o momento em que a viscosidade da mistura resina e catalisador começa a aumentar pelo fato de iniciar o processo de catálise. É nesse instante que ocorre também a perda do poder de penetração devido ao aumento da viscosidade. Quando a tomada de decisão visa somente a velocidade do processo, o tempo de polimento é o fator mais levado em consideração.

\section{MATERIAIS E MÉTODOS}

\section{Materiais}

\section{A Rocha}

A rocha ornamental utilizada neste trabalho é oriunda de um veio de quartzo que corta um corpo pegmatítico, na qual através do ensaio de ICP-OES (espectrometria de emissão óptica com plasma) foi possível detectar que a mesma possui cerca de 99,8\% em $\mathrm{SiO}_{2}$, caracterizando assim um quartzo de alta pureza. Contudo algumas de suas descontinuidades e falhas permitiram que fluidos de percolação infiltrassem na rocha. É possível visualizar na figura 6 , na área demarcada em uma parede de um veio de quartzo que corta o corpo pegmatítico.

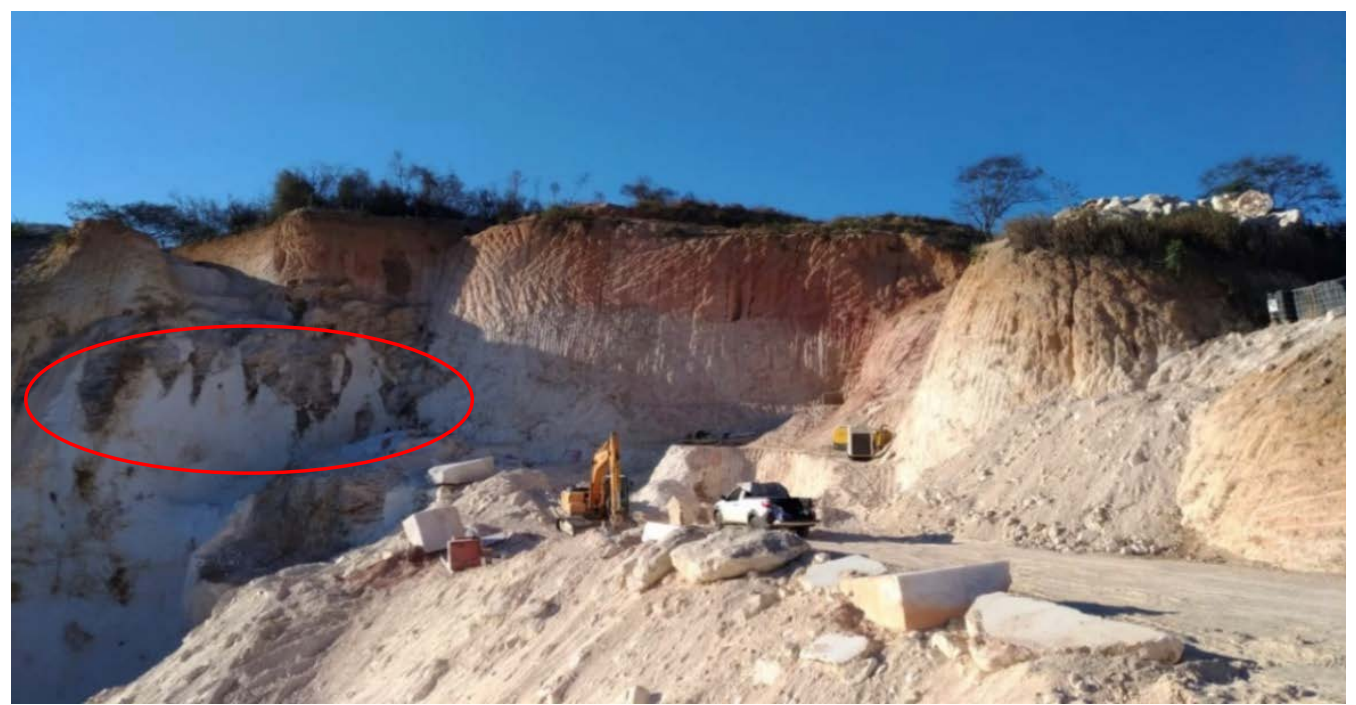

Figura 6 - Frente de lavra do veio de quartzo que corta um pegmatito. Notar para a parede do veio com infiltração (em vermelho).

A rocha está localizada na região leste de Minas Gerais, na Folha de Ataléia, na qual está delimitada pelos meridianos $18^{\circ} 00^{\prime}$ e $18^{\circ} 30^{\prime}$ de latitude sul e $41^{\circ} 00^{\prime}$ e $41^{\circ} 30^{\prime}$ de longitude a oeste de Greenwich, ocupando uma área de aproximadamente $3.000 \mathrm{~km}^{2}$.

A área citada está localizada a leste da Serra do Espinhaço, nos vales do Jequitinhonha, Mucuri e Doce, em domínios dos Cinturões de Araçuaí e Atlântico, como definidos geograficamente, ou englobando a porção norte do Cinturão Ribeira, de Silva et al. (Codemig,1998). A Folha de Ataléia está dividida em três domínios 9estruturais denominados: oriental, ocidental e dos granitos.

O primeiro engloba os gnaisses kinzigíticos, Granito Ataleia e Leucogranito Carlos Chagas. O segundo, a Formação Tumiritinga, Tonalito Galiléia e o Tonalito São Vitor. O terceiro, os granitos tardi-a-pós-tectônicos. Observam-se que o metamorfismo da área cresce gradativamente de oeste para leste, fato que coincide com o aumento da deformação.

Observa-se nos dois primeiros domínios, foliações com direções muito semelhantes, diferindo, no entanto, o sentindo de seus mergulhos. Quanto ao terceiro domínio, mostra uma foliação incipiente principalmente nas bordas dos batólitos, e uma lineação de fluxo desorganizada compatível com o processo intrusivo. Através de imagens de satélites nota-se grandes feições estruturais (fraturas/ e ou falhas), principalmente nas direções NE e NW, sendo as primeiras cortadas pelas segundas e observandose um pequeno rejeito entre os dois sistemas.

Ainda de acordo com Codemig (1998), os bens de maior interesse econômico na região abrangida pela Folha Ataléia estão relacionados 
a pegmatitos, como água marinha, quartzo rosáceo e turmalina.

\section{A extração do material rochoso}

O trabalho de extração do quartzo é realizado no veio encoberto pelo solo local em um topo de uma cadeia montanhosa, na qual, com o auxílio de máquinas se realiza o decapeamento do material inconsolidado para o posterior corte do ponto de interesse, assim transformados em blocos com destino ao beneficiamento (Figura 7).

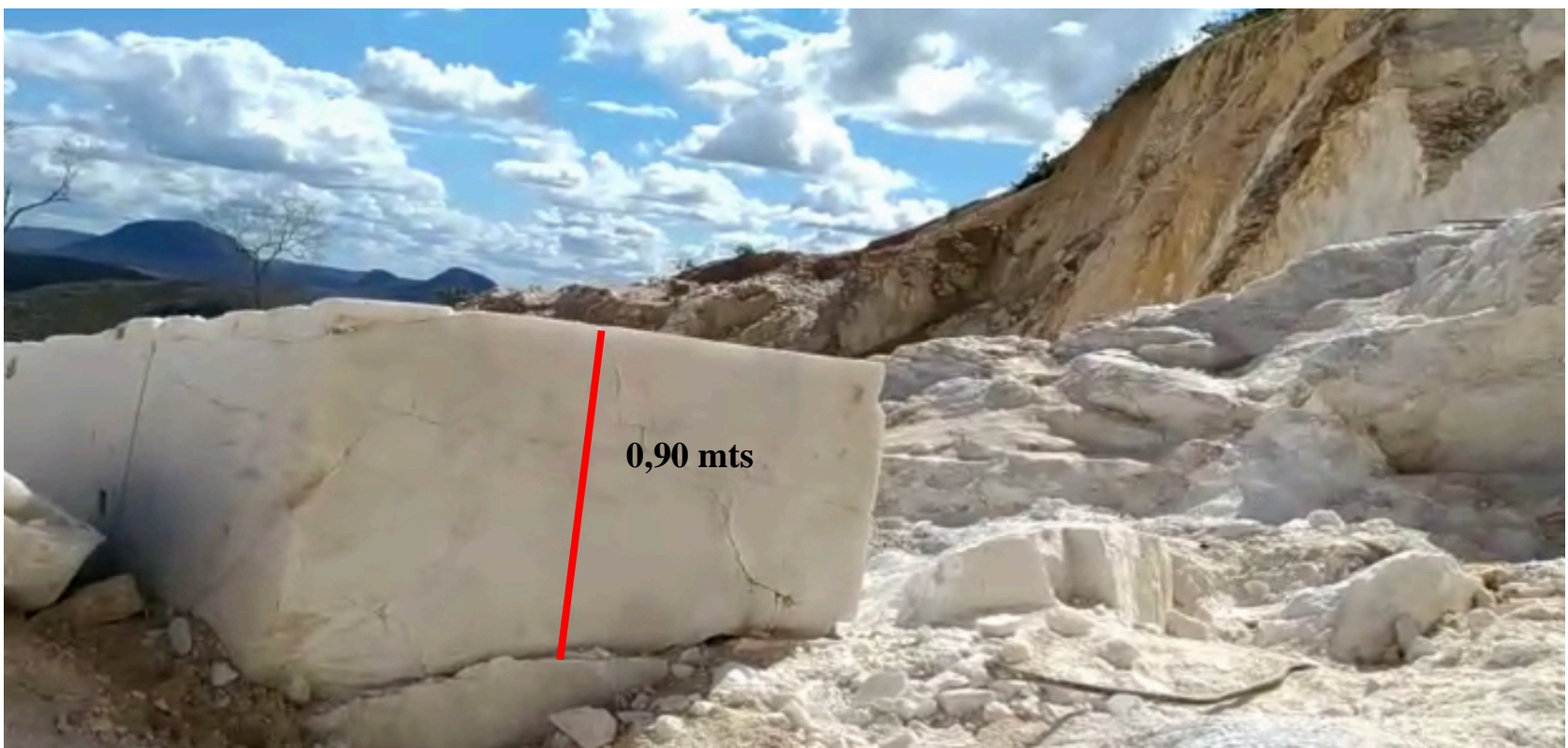

Figura 7 - Bloco de quartzo já esquadrejado com a utilização da tecnologia de fio diamantado.

\section{Os Sistemas Epóxi}

Para a realização do experimento, foram selecionados três tipos de resinas e quatro tipos de catalisadores com o objetivo de gerar quatro sistemas epóxi.

As resinas e os endurecedores foram escolhidos a cargo de gerar sistemas com características diferentes entre si, seja na viscosidade, tempo de gel, tempo de catálise e período pré-polimento, a fim de comparar os possíveis diferentes resultados obtidos no brilho das chapas polidas em relação às características das misturas, na qual essas características serão demonstradas nas tabelas 2 e 3.

Todos os testes realizados para encontrar as viscosidades dos produtos, foram realizados com viscosímetro digital da Mry de série VR3000, rotacional para rápida determinação da viscosidade de acordo com a ISO 2555 e várias normas ASTM onde os resultados obtidos são 100\% compatíveis com o método Brookfield, que consiste em um elemento rotante de forma cilíndrica ou em disco, inserido em um recipiente cilíndrico contendo o fluido do qual se deseja medir a viscosidade (ABNT-NBR 9393).

A partir da mistura da resina com o endurecedor é formada uma nova característica de viscosidade para o sistema epóxi, na qual está descrita na tabela 4, juntamente com as demais particularidades de cada sistema.

Tabela 2 - Relação entre resina e sua característica de viscosidade.

\begin{tabular}{c|c}
\hline Resina & Viscosidade (mPa.s) a $\mathbf{2 5}^{\circ} \mathbf{C}$ \\
\hline Resina A & $900-3100$ \\
\hline Resina B & $500-600$ \\
\hline Resina C & $300-400$ \\
\hline
\end{tabular}

Tabela 3 - Propriedades de viscosidade, tempo de gel, tempo de catálise e tempo para polimento, dos endurecedores que serão utilizados na formação dos sistemas epóxi.

\begin{tabular}{l|c|c|c|c|c}
\hline \multirow{2}{*}{ Endurecedores } & \multirow{2}{*}{$\begin{array}{c}\text { Viscosidade } \\
\text { (mPa.s) a 25 } \mathbf{5}^{\circ} \mathbf{C}\end{array}$} & $\begin{array}{c}\text { Tempo de Gel (min) a } \\
\mathbf{2 5}^{\mathbf{0}} \mathbf{C}\end{array}$ & \multicolumn{2}{|c|}{ Tempo de Catálise (min) } & $\begin{array}{c}\text { Tempo para } \\
\text { Polimento } \\
\text { (hs) a 25 } \mathbf{C}\end{array}$ \\
\hline Endurecedor A & $40-100$ & 55 a 75 & Aprox. 240 & 210 & 24 \\
\hline Endurecedor B & $50-150$ & 50 a 70 & 300 a 360 & 180 a 200 & 48 \\
\hline Endurecedor C & $20-50$ & 60 a 75 & 200 a 220 & 120 a 150 & 24 \\
\hline Endurecedor D & $30-60$ & 150 a 280 & 300 a 360 & 240 a 280 & 48 \\
\hline
\end{tabular}


Tabela 4 - Características dos sistemas epóxi que serão utilizados no experimento.

\begin{tabular}{|c|c|c|c|c|c|c|}
\hline $\begin{array}{l}\text { Sistema } \\
\text { Epóxi }\end{array}$ & Resina & Endurecedor & $\begin{array}{l}\text { Viscosidade do } \\
\text { Sistema a } 25^{\circ} \mathrm{C} \\
\text { (mPa.s) }\end{array}$ & $\begin{array}{l}\text { Tempo de Gel } \\
\text { do Sistema a } \\
25^{\circ} \mathrm{C}(\mathrm{min})\end{array}$ & $\begin{array}{l}\text { Tempo de Catálise } \\
\text { do Sistema a } 25^{\circ} \mathrm{C} \\
\text { (min) }\end{array}$ & $\begin{array}{c}\text { Tempo de } \\
\text { Polimento do } \\
\text { Sistema a } 25^{\circ} \mathrm{C}(\mathrm{hs})\end{array}$ \\
\hline I & Resina A & Endurecedor A & $351-357$ & 55 a 75 & Aprox. 240 & 24 \\
\hline II & Resina B & Endurecedor B & $174-176$ & 50 a 70 & 300 a 360 & 48 \\
\hline III & Resina B & Endurecedor D & $165-167$ & 150 a 280 & 300 a 360 & 48 \\
\hline IV & Resina C & Endurecedor C & $151-152$ & 60 a 75 & 200 a 220 & 24 \\
\hline
\end{tabular}

Assim os sistemas epóxi utilizados se definem pelas seguintes propriedades:

- $\quad$ Sistema Epóxi I - Mistura de alta viscosidade com um tempo de catálise e gel acelerados e um tempo médio para polimento.

- $\quad$ Sistema Epóxi II - Produto com viscosidade mediana, tempo de gel acelerado, tempo de catálise mediano e um tempo mais lento de polimento.

- $\quad$ Sistema Epóxi III - Produto com baixa viscosidade, tempo longo para atingir o gel, tempo mediano para catálise e um tempo mais lento para polimento

- $\quad$ Sistema Epóxi IV - Mistura com baixa viscosidade, tempo de catálise e gel acelerados, e um tempo médio para polimento.

Assim, o sistema I tende a ser um sistema de menor penetração de acordo com suas características de alta viscosidade e um tempo de gel e catálise curtos, possuindo menor capacidade de atingir a profundidade dos poros e microfissuras, enquanto o sistema II se qualifica por ser um sistema de viscosidade intermediária, com uma penetração considerada mediana, ou seja, aquela que não irá ficar somente na superfície da rocha mas também não iria alcançar os pontos mais profundos, já o sistema III se caracteriza por ser uma mistura de alto poder de penetração pelo fato de possuir uma viscosidade baixa e o maior tempo de gel dentre as demais misturas, ou seja, dentre todos os sistemas utilizados, é o que melhor irá conseguir penetrar na rocha, logo o sistema IV se define por possuir a menor viscosidade dentre os quatros, porém não tem o mesmo poder de penetração que o III devido a alcançar o tempo de gel em um período mais curto.

Para originar os sistemas epóxi foram analisadas quais as diferentes características que necessitavam para estar comparando possíveis distintos resultados no brilho da rocha. Deste modo, através das fichas técnicas dos produtos utilizados, foi selecionada resina e endurecedores que formaram diferentes sistemas na qual deveriam ter pelo menos duas características distintas, levando em conta a característica da rocha que foi utilizada para o teste.

\section{Equipamentos utilizados nos processos Etapas de Telagem e Resinagem}

As etapas de telagem e resinagem foram realizadas em uma linha de resinagem automática, contendo 1 forno vertical de secagem com capacidade para 20 chapas, um dispenser vertical de descanso com capacidade para 10 chapas e um forno de catálise vertical com capacidade para 40 chapas.

O equipamento ainda possui 2 robôs com 36 ventosas cada, na qual são responsáveis pela movimentação de entrada e saída de chapas da linha, as chapas se movimentam na linha através de bandejas na qual são movidas pelo sistema de engrenagens e correntes.

Para alimentação dos fornos e dispenser a linha possui 3 elevadores responsáveis pela entrada e retirada das chapas dos fornos e do dispenser.

Todo o sistema de aquecimento dos fornos é realizado através da queima de GLP. O sistema de automatização do equipamento possibilita controlar a temperatura dos fornos, podendo variar de $35^{\circ} \mathrm{C}$ a $65^{\circ} \mathrm{C}$.

O forno de secagem, ilustrado pela figura 8, através do calor gerado pela queima de gás, é equipamento responsável por eliminar a umidade presente nas chapas e consequentemente dilatar os poros e microfissuras presentes na mesma, para possibilitar uma resinagem de melhor qualidade pelo fato da resina conseguir penetrar melhor na superfície do material, além de que, para haver a catálise dos sistemas epóxi utilizados na telagem e resinagem é necessário que as chapas estejam livres de umidade.

O dispenser de gel, ilustrado na figura abaixo, é o equipamento responsável por fornecer a área 
de descanso das chapas, para que o sistema epóxi inicie o seu processo de catálise na qual há o aumento da viscosidade da mistura, esse é o momento de observar se todos os poros, fissuras e microfissuras foram preenchidos pela a resina; o equipamento não trabalha com calor gerado pela queima de gás, somente com a temperatura ambiente.

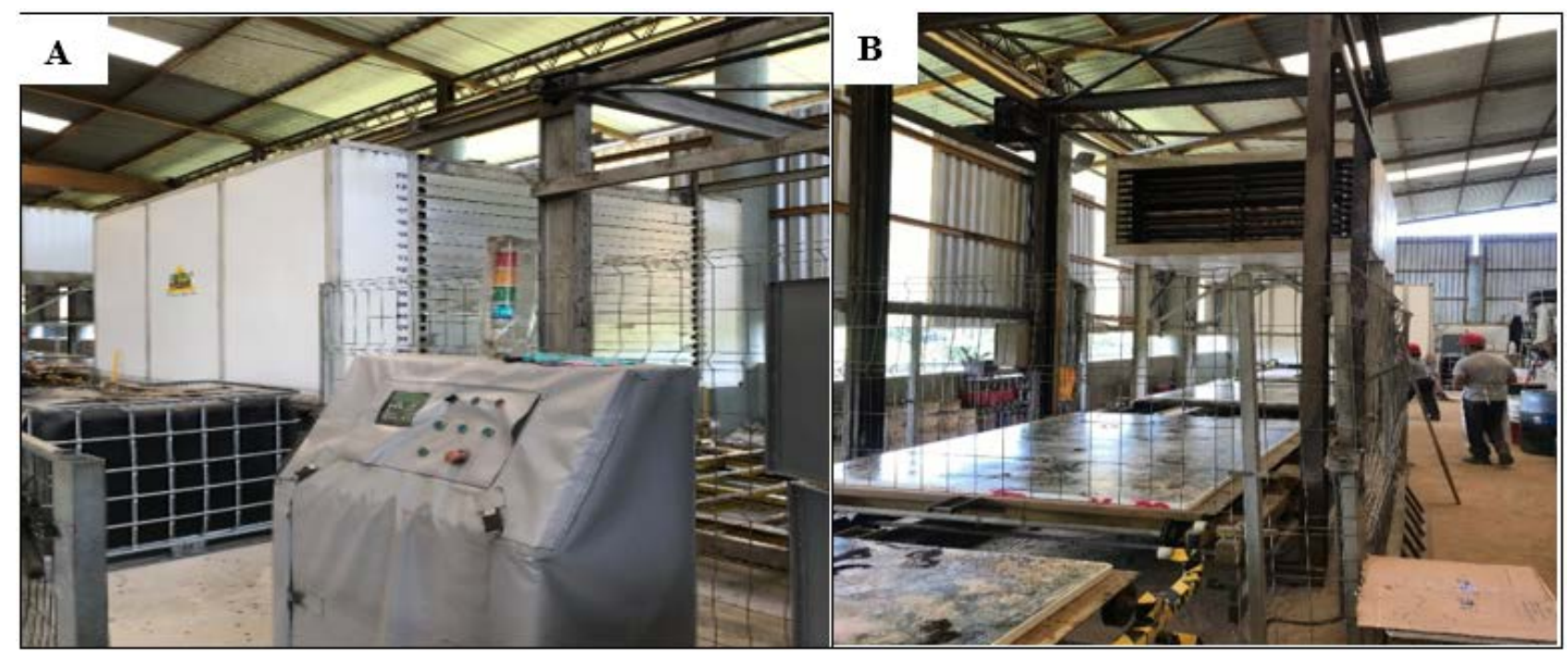

Figura 8 - A) - Vista para o forno de secagem da linha automática de resinagem. B) - Vista da linha de resinagem com destaque para o dispenser de gel.

O forno de catálise, já ilustrado na figura 5, através do calor gerado pela queima de gás, é o equipamento encarregado por acelerar o tempo de catálise do produto. Além dos equipamentos que contemplam o forno automático de resina, foram utilizados os materiais abaixo para a realização do processo de resinagem e telagem, na qual estão ilustrados na figura 9 .

- Recipiente com capacidade de 2 L - Locais de armazenamento das porções de resina e endurentes e de realizar as misturas para a confecção dos sistemas epóxi que foram utilizados no experimento.

- Vareta de Polímero - Utilizada para realizar a mistura no momento de formação dos sistemas epóxi.

- Balança com capacidade até $3 \mathrm{~kg}$ - Utilizada para pesar a quantidade de resina e endurente que será utilizada para a formação dos sistemas epóxi.

- Rolos de espuma - Utilizado para espalhar os sistemas epóxi sobre a superfície das chapas.

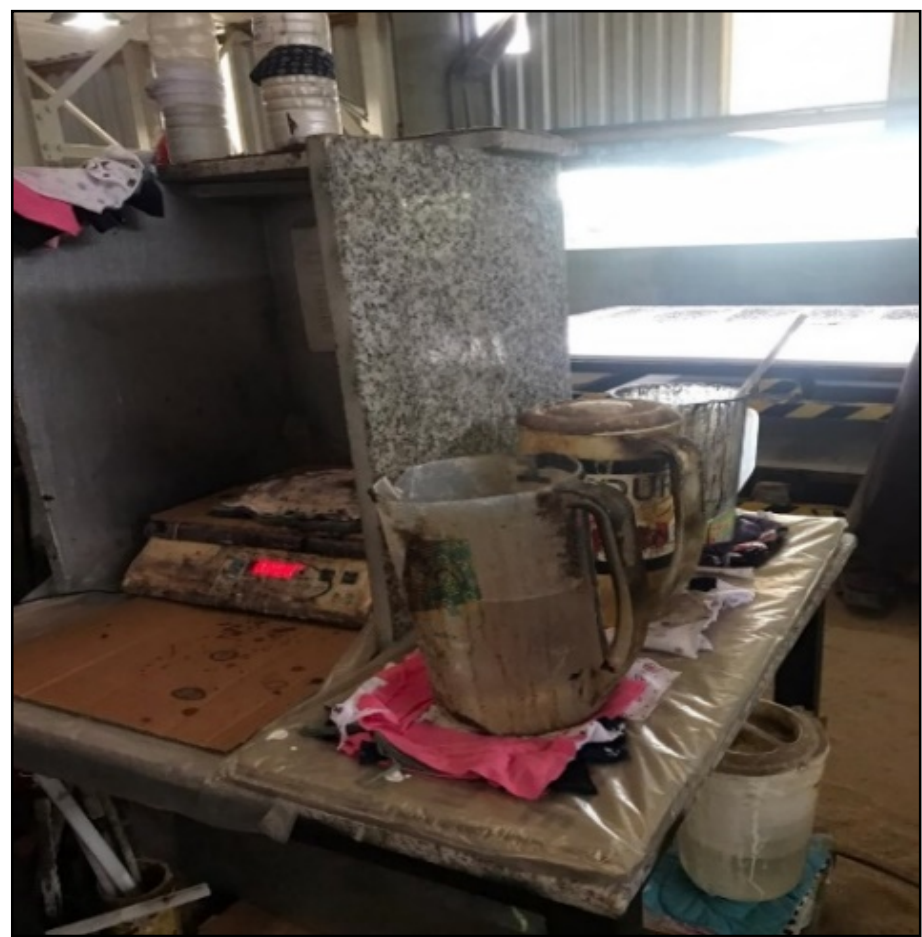

Figura 9 - Balança, jarras e vareta - materiais utilizados para a formulação dos sistemas epóxi. 


\section{Etapas de Levigamento e Polimento}

Para a realização dos processos de levigamento e polimento foi utilizada uma politriz automática Breton "KG 4000 PLUS", apresentada na figura 10 , máquina composta por 19 mandris, cada mandril dispondo de um conjunto de oito suportes para abrasivos.

$O$ processo de passagem das chapas na máquina, inicia com a utilização de um robô carregador que realiza a coleta das chapas disposta em um cavalete, na qual o mesmo faz o transporte dessas até as mesas de transporte, na qual essas mesas com o auxílio de rolos conectados entre sim por um sistema de corrente mecânica realiza a movimentação até uma esteira confeccionada por polímero, é quando as chapas se encontram sobre a esteira que os processos de polimento e levigamento são realizados, ou seja as chapas são transportadas no interior da máquina somente pela a esteira.

Da mesma forma que as chapas são transportadas do robô coletor até a esteira, elas também são transportadas da esteira até o robô descarregador, dessa forma finalizando todo o ciclo da máquina.

\section{Aferição do Brilho}

Para realizar a aferição do brilho das superfícies das chapas empregadas no experimento, foi utilizado um Glossímetro “BYK - Gardener GmbH”.

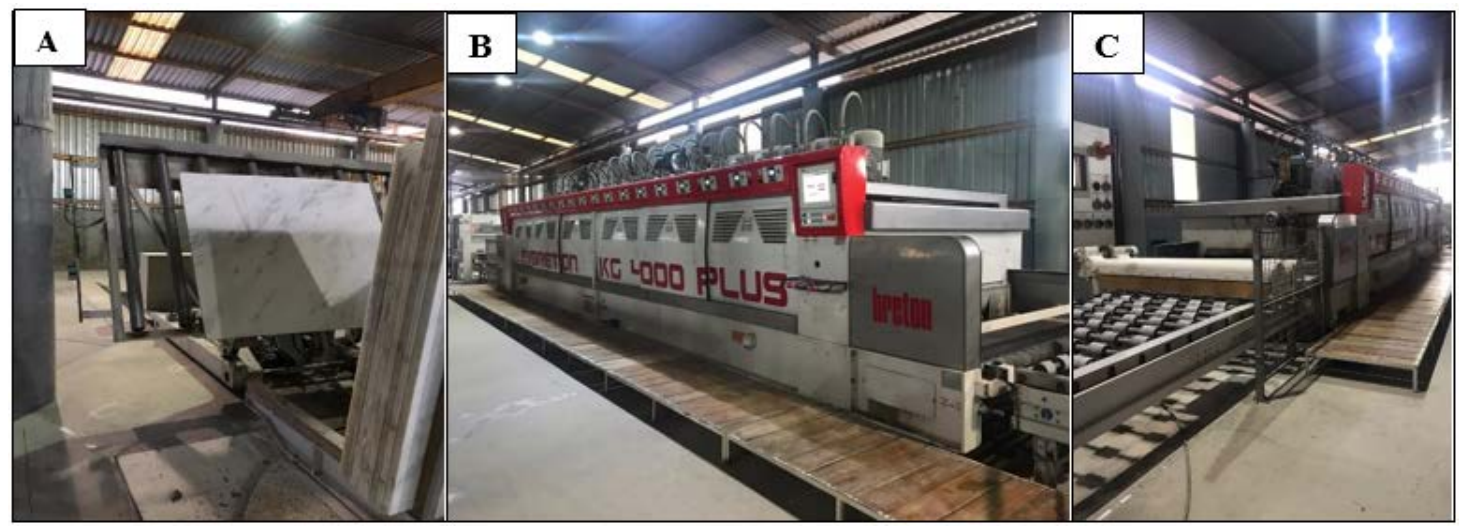

Figura 10 - a) - Robô de entrada da politriz. b) - Politriz Levibreton kG 4000 plus. C) - Mesa de transporte após a saída da politriz.

\section{$O$ processo de beneficiamento da rocha}

Abaixo segue as etapas do processo de beneficiamento da rocha, a partir do desdobramento do bloco em chapas.

- $1^{\circ}$ Etapa: Telagem - Momento em que é aplicada no verso da chapa uma manta composta por fibra de vibro, na qual essa é coberta com o sistema epóxi, a fim de conferir a rocha maior resistência mecânica para o manuseio e utilização da mesma.

- $2^{\circ}$ Etapa: Restauração - Nesse momento são preenchidas as partes fraturadas e fissuradas da rocha, o processo é feito com a inserção de pedaços da própria rocha em granulometria diferente, sempre a granulometria menor sobrepondo a maior, o sistema epóxi é utilizado nesse processo para fornecer a soldagem entre os grãos que foram utilizados para a restauração e a superfície da rocha.

- $3^{\circ}$ Etapa: Reforço - Após o desbaste das restaurações através da utilização de lixas diamantadas, a chapa retorna para a resinagem para a aplicação do sistema epóxi em toda sua superfície, a fim de preencher os poros e as fissuras que no processo anterior não foi restaurada, dessa forma elevando a resistência mecânica do material.

- $4^{\circ}$ Etapa: $1^{\circ}$ Levigamento - Nessa fase o material é submetido ao um processo de calibração da superfície da chapa, na qual o mesmo é realizado em uma máquina chamada levigadora, essa máquina é composta por mandris que contém suportes para a fixação dos abrasivos. Os abrasivos são as ferramentas de desbaste responsáveis por promover a calibração da superfície, assim tirando o aspecto rugoso do material e o tornando liso, completamente plano. Nessa etapa não o intuito de conceder brilho a superfície, o objetivo e torna-la lisa e plana.

- $5^{\circ}$ Etapa: $1^{\circ}$ Demão de resinagem - O que se chama de $1^{\circ}$ demão de resinagem consiste na aplicação do sistema epóxi após o processo de levigamento, pois quando submetido ao atrito gerado pelos abrasivos, a rocha tende a formar algumas novas fissuras ou até mesmo é desfeito algumas partes que foram restauradas.

- $6^{\circ}$ Etapa: Corte da Resina - É a etapa na qual a resina é cortada através de abrasivos 
menos agressivos, pois não mais é necessário plainar a superfície da chapa, o momento é de somente retirar o excesso de resina que está acima da superfície da chapa, e preparar a mesma para a resinagem na qual será realizado o polimento.

- $7^{\circ}$ Etapa: $2^{\circ}$ Demão de resinagem Nessa etapa a superfície da chapa já se encontra praticamente sem nenhuma fissura visível, podem existir ainda algumas microfissuras, que serão preenchidas através da aplicação do sistema epóxi nesse processo, é a última resinagem da chapa, é o momento que antecede o polimento.

- $8^{\circ}$ Etapa: Polimento - Fase de acabamento da superfície da chapa, é retirada toda a resina superficial da chapa, deixando apenas aquelas que estão nos preenchimentos dos poros, das fissuras, microfissuras e nas restaurações, contudo nesse momento é fornecido brilho a rocha através da utilização de uma maior diversidade de abrasivos, na qual os grãos utilizados nos abrasivos vão afiando respectivamente de acordo com a quantidade de mandris utilizados, até chegar no momento em que a chapa possua brilho e nenhum arranhão, ou seja, os abrasivos deverão retirar sempre do seu antecessor o arranhão que foi gerado pelo atrito entre abrasivo e rocha.

\section{A aplicação dos Sistemas Epóxi}

Antes de realizar a aplicação do sistema, é necessário proceder com a formulação dele através da mistura de resina e endurente, na qual se chama respectivamente de Parte A e Parte B. A proporção e a compatibilidade dos endurente utilizados para a formulação do sistema Epóxi é informado pelo fabricante através da ficha técnica de cada produto, é necessário que siga rigorosamente a proporção indicada pelo fabricante para assegurar as características já informadas de viscosidade, tempo de gel, tempo de catálise e tempo para polimento.

Segue abaixo a proporção de mistura referente a utilização de Parte B no sistema epóxi (Tabela 5).

O sistema epóxi é pesado e misturado em uma jarra, na qual se insere primeiro o volume de resina desejado e a proporção do endurente compatível para a formulação do sistema, na qual após os dois produtos inseridos no recipiente é realizada a mistura de forma manual entre os componentes, de forma manual também o sistema é lançado sobre a chapa, na qual posteriormente o mesmo é espalhado em toda a superfície da rocha através da utilização de um rolo poliéster, assim formando uma camada uniforme do produto (Figura 11).

Nas tabelas 6, 7, 8 e 9 são mostradas as frações de resinas e endurentes utilizados para a formulação do Sistema Epóxi.

Tabela 5 - Proporção de parte B nos sistemas epóxi.

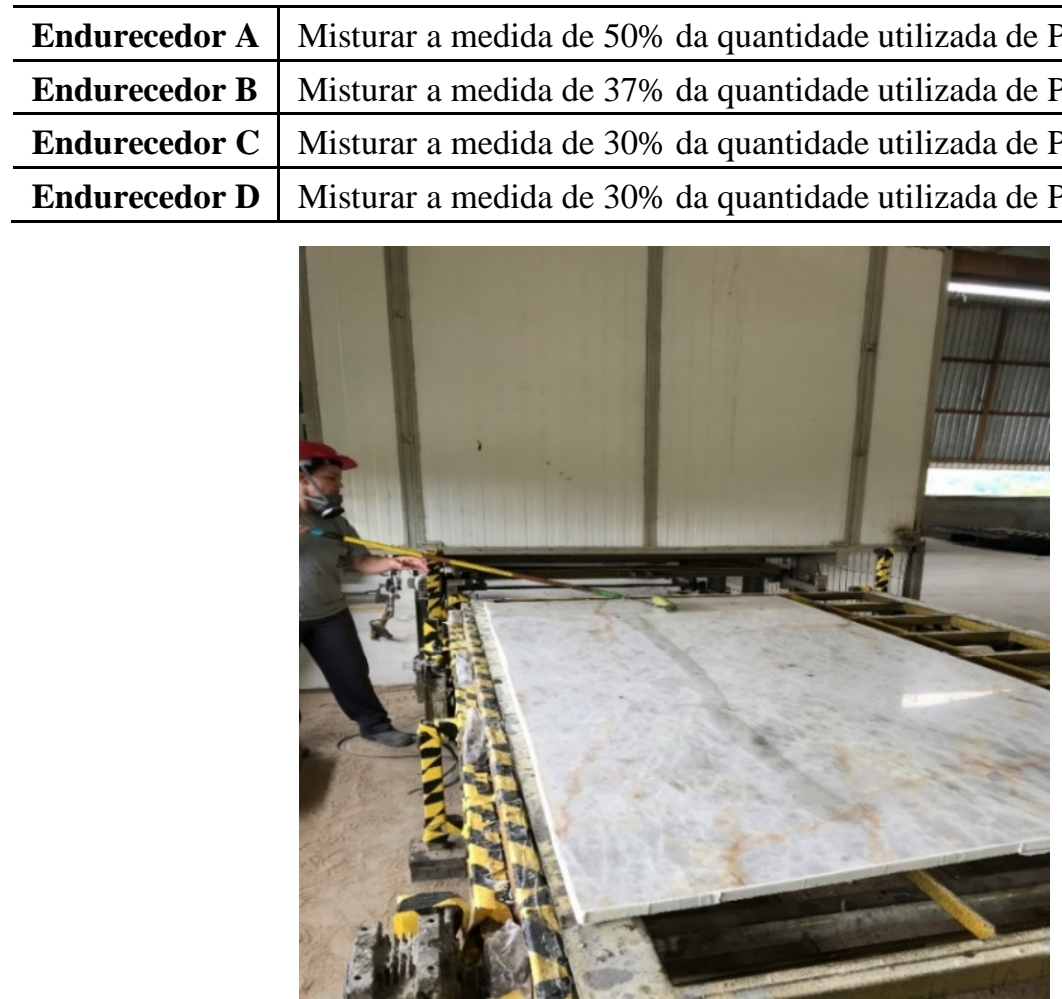

Figura 11 - Momento da aplicação do sistema epóxi com a utilização do rolo de espuma, em uma das chapas utilizada no experimento. 
Tabela 6 - Quantidade de resina e endurecedor utilizados em cada processo da chapa A.

\begin{tabular}{c|c|c|c|c}
\hline \multicolumn{4}{c}{ Sistema Epóxi I - Referência da chapa de aplicação: A } \\
\hline \multirow{2}{*}{ Processo } & \multicolumn{2}{|c|}{ Resina } & \multicolumn{2}{c}{ Endurecedor } \\
\cline { 2 - 5 } & Nome & Quantidade (kg) & Nome & Quantidade (kg) \\
\hline Telagem & Resina A & 0,500 & Endurecedor A & 0,250 \\
\hline Restauração & Resina A & 0,500 & Endurecedor A & 0,250 \\
\hline Reforço & Resina A & 0,300 & Endurecedor A & 0,150 \\
\hline $1^{\circ}$ Demão de Resinagem & Resina A & 0,200 & Endurecedor A & 0,100 \\
\hline $2^{\circ}$ Demão de Resinagem & Resina A & 0,200 & Endurecedor A & 0,100 \\
\hline
\end{tabular}

Tabela 7 - Quantidade de resina e endurecedor utilizados em cada processo da chapa B.

\begin{tabular}{c|c|c|c|c}
\hline \multirow{4}{*}{ Processo } & \multicolumn{2}{|c|}{ Resina } & \multicolumn{2}{c}{ Endurecedor } \\
\cline { 2 - 5 } & Nome & Quantidade (kg) & Nome & Quantidade (kg) \\
\hline Telagem & Resina B & 0,500 & Endurecedor B & 0,185 \\
\hline Restauração & Resina B & 0,500 & Endurecedor B & 0,185 \\
\hline Reforço & Resina B & 0,300 & Endurecedor B & 0,111 \\
\hline $1^{\text {o }}$ Demão de Resinagem & Resina B & 0,200 & Endurecedor B & 0,074 \\
\hline $2^{\text {o }}$ Demão de Resinagem & Resina B & 0,200 & Endurecedor B & 0,074 \\
\hline
\end{tabular}

Tabela 8 - Quantidade de resina e endurecedor utilizados em cada processo da chapa C.

\begin{tabular}{c|c|c|c|c}
\hline \multicolumn{4}{c}{ Sistema Epóxi III - Referência da chapa de aplicação: C } \\
\hline \multirow{2}{*}{ Processo } & \multicolumn{2}{|c|}{ Resina } & \multicolumn{2}{c}{ Endurecedor } \\
\cline { 2 - 5 } & Nome & Quantidade (kg) & Nome & Quantidade (kg) \\
\hline Telagem & Resina B & 0,500 & Endurecedor D & 0,150 \\
\hline Restauração & Resina B & 0,500 & Endurecedor D & 0,150 \\
\hline Reforço & Resina B & 0,300 & Endurecedor D & 0,090 \\
\hline $1^{\circ}$ Demão de Resinagem & Resina B & 0,200 & Endurecedor D & 0,060 \\
\hline $2^{\circ}$ Demão de Resinagem & Resina B & 0,200 & Endurecedor D & 0,060 \\
\hline
\end{tabular}

Tabela 9 - Quantidade de resina e endurecedor utilizados em cada processo da chapa D.

\begin{tabular}{c|c|c|c|c}
\hline \multicolumn{4}{c}{ Sistema Epóxi IV - Referência da chapa de aplicação: D } \\
\hline \multirow{2}{*}{ Processo } & \multicolumn{2}{|c}{ Resina } & \multicolumn{2}{c}{ Endurecedor } \\
\cline { 2 - 5 } & Nome & Quantidade (kg) & Nome & Quantidade (kg) \\
\hline Telagem & Resina C & 0,500 & Endurecedor C & 0,150 \\
\hline Restauração & Resina C & 0,500 & Endurecedor C & 0,150 \\
\hline Reforço & Resina C & 0,300 & Endurecedor C & 0,090 \\
\hline $1^{\text {o }}$ Demão de Resinagem & Resina C & 0,200 & Endurecedor C & 0,060 \\
\hline $2^{\circ}$ Demão de Resinagem & Resina C & 0,200 & Endurecedor C & 0,060 \\
\hline
\end{tabular}

\section{O Levigamento}

Como já descrito no processo de beneficiamento da rocha, o levigamento é o processo responsável por desbastar a chapa, de forma a eliminar a rugosidade da mesma e calibrar a superfície, eliminando todas as marcas oriundas do processo de serrada.

Para tanto foi utilizada a sequência de abrasivos que segue na tabela 10, variando entre abrasivos diamantados, convencionais e resinoides.

Os abrasivos diamantados, ilustrado na figura 12A, são compostos por uma liga metálica que envolve os diamantes, na qual os diamantes são responsáveis pelo poder de corte do produto, quanto maior for a granulometria do elemento de corte maior o poder remoção da ferramenta. No levigamento das chapas utilizadas no experimento foram utilizados abrasivos diamantados das granulometrias de 36 até 220 mesh.

Finalizando o processo de o levigamento foram utilizados abrasivos convencionais e resinoides, os abrasivos convencionais, ilustrado 
na figura 12B, são formados por cimento sorel tendo o carbeto de silício como a elemento cortante. Os abrasivos resinoides, ilustrado na figura 13C, são formados por uma matriz epoxídica tendo diamantes como elementos de corte. Na tabela 10 consta a sequência de abrasivos utilizados no processo de levigamento nessa pesquisa.

\section{O Corte de Resina}

Já com a superfície plana e livre de imperfeições originadas pela serrada, no corte de resina não necessita da utilização de abrasivos diamantados, assim muda a configuração dos abrasivos utilizados no processo de corte de resina, na qual abaixo consta a sequência de abrasivos utilizados (Tabela 11).

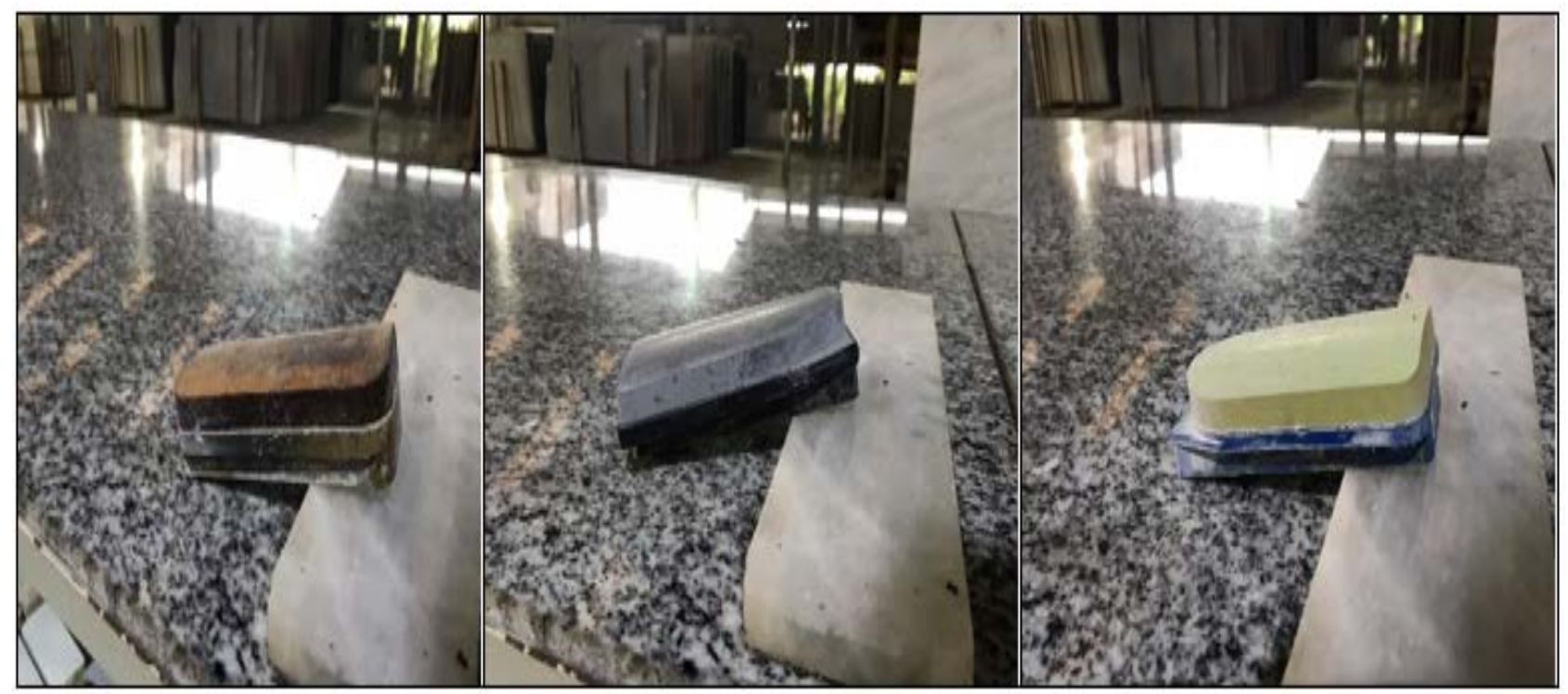

Figura 12 - A) - Peça de abrasivo diamantado; B) - Peça de abrasivo convencional; C) - Peça de abrasivo resinoide.

Tabela 10 - Sequência de abrasivos utilizados no processo de levigamento.

\begin{tabular}{l|r|r|r|r|r|r|r|r|r|r|r}
\hline \multicolumn{10}{c}{ Processo de Levigamento } \\
\hline $\mathbf{1}$ & 2 & 3 & 4 & 5 & 6 & 7 & 8 & 9 & 10 & 11 & 12 \\
\hline $\mathbf{3 6}$ & 46 & 46 & 60 & 80 & 120 & 150 & 220 & 120 & 220 & 220 & 320 \\
\hline \multicolumn{10}{|c|}{ Diamantado } & Convencional & Resinoide \\
\hline
\end{tabular}

Tabela 11 - Sequência de abrasivos utilizados no processo de corte de resina.

\begin{tabular}{l|c|c|c|c|c|c}
\hline \multicolumn{7}{c}{ Processo de Corte de Resina } \\
\hline \multicolumn{1}{|c}{ Mandril } \\
\hline $\mathbf{1}$ & $\mathbf{2}$ & $\mathbf{3}$ & $\mathbf{4}$ & $\mathbf{5}$ & $\mathbf{6}$ & $\mathbf{7}$ \\
\hline $\mathbf{1 2 0}$ & 220 & 120 & 150 & $180 / 220$ & 320 & 400 \\
\hline
\end{tabular}

\section{O polimento}

Como o processo de polimento visa fornecer brilho a superfície, faz-se necessário utilizar abrasivos com granulometria mais finas, sendo assim a quantidade de abrasivos utilizados no processo de polimento é maior que nos processos de levigamento e de corte de resina, pois quanto mais fino for o elemento de corte do rebolo abrasivo, menor será o risco gerado na superfície da chapa, assim fornecendo maior brilho. A Tabela 12, a seguir, representa a sequência de abrasivos utilizados no processo de polimento.

Os parâmetros de configurações de máquina, como velocidade de esteira, velocidade de trave, pressões exercidas sobre a superfície rochosa, vazão de água e sequência de abrasivos foram utilizados identicamente em todas as chapas, a fim de não possibilitar que nenhuma variável, além da utilização de diferentes sistemas epóxi, permitisse alterar o brilho final das superfícies.

\section{A aferição do brilho}

O brilho foi aferido com as chapas em posição vertical, na qual para padronização da medição foram traçadas 3 (três) alinhamentos, que podem ser observadas nas figuras abaixo, com $o$ intuito de direcionar 0 posicionamento do glossímetro, de modo a aferir áreas similares nas diferentes superfícies avaliadas.

Para ter um resultado com maior demonstração do brilho que representa a superfície das chapas, foram realizadas 30 (trinta) aferições para cada alinhamento, deste modo totalizando 90 medições por chapa, na qual o próprio glossímetro forneceu o brilho médio das medições realizadas em cada chapa. 
Tabela 12 - Sequência de abrasivos utilizados no processo de polimento.

\begin{tabular}{|c|c|c|c|c|c|c|c|c|c|c|c|}
\hline \multicolumn{12}{|c|}{ Processo de polimento } \\
\hline \multicolumn{12}{|c|}{ Mandril } \\
\hline 1 & 2 & 3 & 4 & 5 & 6 & 7 & 8 & 9 & 10 & 11 & 12 \\
\hline 120 & 2200 & 120 & 150 & $180 / 220$ & 220 & 320 & 400 & 400 & 600 & 600 & 800 \\
\hline \multicolumn{2}{|c|}{ Magnesiano } & \multicolumn{10}{|c|}{ Resinoide } \\
\hline 13 & 14 & 15 & 16 & 17 & 18 & 19 & & & & & \\
\hline 800 & 1200 & 1200 & 1500 & 2600 & 3000 & 6000 & & & & & \\
\hline \multicolumn{7}{|c|}{ Resinoide } & & & & & \\
\hline
\end{tabular}

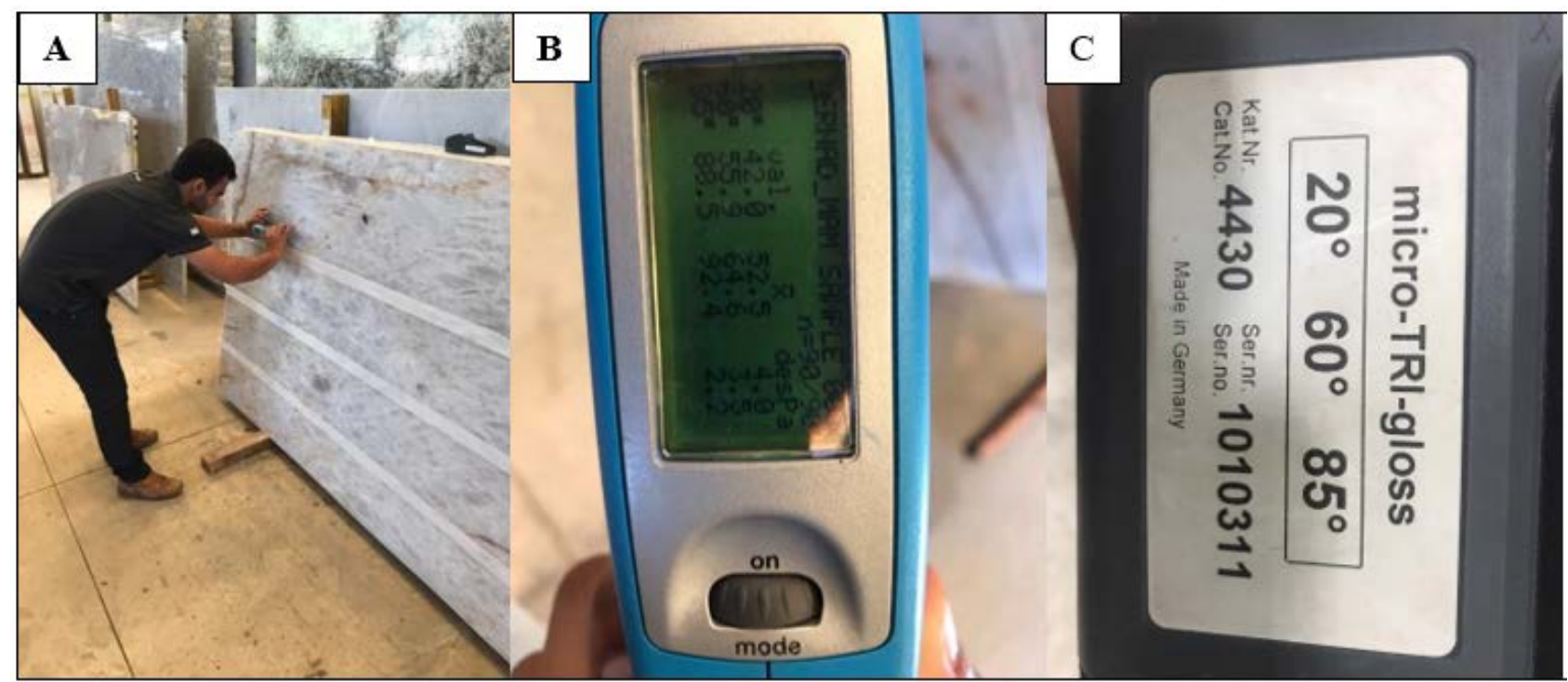

Figura 13 - A) Executando a aferição do brilho no $1^{\circ}$ alinhamento da superfície da chapa; B) - Ilustração do resultado do brilho aferido na chapa C, na qual foi utilizado o sistema epóxi 3; C) - registro no glossímetro dos ângulos de aferições de brilho.

O glossímetro utilizado afere o brilho em três perspectivas, que são elas, $20^{\circ}, 60^{\circ}$ e $85^{\circ}$, a diferença entre elas é o ângulo em que o reflexo do brilho é coletado pelo aparelho.

\section{O Corte de Resina}

Já com a superfície plana e livre de imperfeições originadas pela serrada, no corte de resina não necessita da utilização de abrasivos diamantados, assim muda a configuração dos abrasivos utilizados no processo de corte de resina, na qual abaixo consta a sequência de abrasivos utilizados (Tabela 11).

\section{RESULTADOS E DISCUSSÕES}

Para a divulgação do resultado irá ser utilizado a média do brilho medido no ângulo de $60^{\circ}$, seguindo as orientações fornecidas pela norma da ASTM D523-14. Sendo assim a figura 14 ilustra os resultados de brilho obtidos pelas as aferições posteriores ao processo de polimento das chapas A, B, C e D, utilizadas no experimento.

Analisando os dados apresentados no gráfico acima, é possível constatar que o sistema epóxi tem influência na pontuação de brilho da superfície da rocha quando submetida ao processo de polimento.

Dentre as 4 misturas utilizadas, a maior desigualdade de pontuação dos brilhos medidos, ficou entre o sistema IV e o sistema III, apresentando 14,6 GU, tendo sistema IV originado 70,5 GU e o sistema III proporcionado 55,9 GU. A menor diferença foi representada entre os sistemas I e II, tendo apenas 1,1 ponto de valor de brilho, na qual o sistema I gerou 64,7 GU de brilho e o sistema II 63,7 GU.

Contudo, observando as características dos sistemas epóxi utilizados e os resultados gerados pelas aferições de brilho, o tempo de gel e tempo de catálise foram fatores determinantes, uma vez que o sistema IV que mais originou brilho, tem o menor tempo de gel e o menor tempo de catálise dentre as 4 misturas. Nessa mesma tendência, o sistema I foi o segundo sistema com menor tempo de gel e tempo de catálise, consequentemente o sistema I tem o menor tempo de gel e menor tempo de catálise quando comparado ao III, fato que ocasionou a quarta 


\section{Comparação de brilho entre os Sistemas Epóxi utilizados no experimento

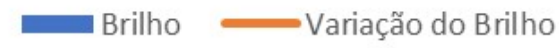

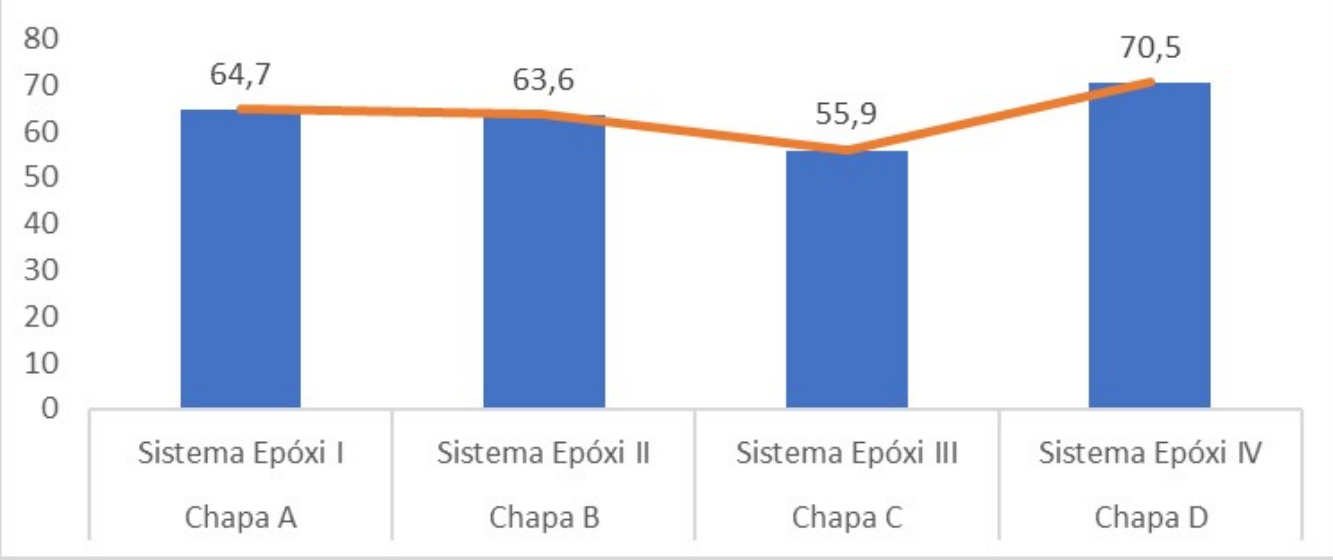

Figura 14 - Resultados das aferições de brilho por chapa de acordo com as aplicações dos sistemas epóxi.

posição ao sistema III e a terceira posição ao sistema I.

Nota-se também que os sistemas que apresentaram a primeira e segunda colocação na pontuação de brilho, possuem tempo de polimento de 24 horas, e os dois últimos colocados possuem tempo de polimento de 48 horas. No entanto, não foi possível correlacionar as características de viscosidades da mistura com a pontuação de brilho, pois o sistema com menor viscosidade teve a maior pontuação, todavia o sistema com a segunda maior pontuação de brilho, possui a maior viscosidade dentre as 4 misturas.
Em virtude dos fatos mencionados o experimento teve um resultado positivo, tornando possível uma correlação de característica de sistemas epóxi com a quantidade de brilho fornecida pela superfície da chapa após o polimento submetido a aplicação de diferentes misturas epoxídicas.

Como sugestão para trabalho futuros, aconselho avaliar rochas com características diferentes da que foi utilizada nesse experimento, ou seja, rochas de menor dureza, com o intuito de entender se as mesmas características de tempo de gel e tempo de catálise irão estar diretamente ligadas aos valores de brilho.

\section{REFERÊNCIAS}

ABIROCHAS- Associação Brasileira da Indústria de Rochas ornamentais. Balanço das Exportações e Importações Brasileiras de Rochas ornamentais no Período JaneiroAgosto de 2019 - Informe 05/2019. Disp. em: https://www.abirochas.com.br/wp-

content/uploads/2019/04/Informe_05_2019_Agosto.pdf.

Acesso em 14-10-2019a.

ABIROCHAS- Associação Brasileira da Indústria de Rochas ornamentais. Exportações Brasileiras Superam Expectativas em 2019. ABIROCHAS. Disp. em: https://www.ab irochas.com.br/wp-content/uploads/2019/05/exportacoes-brasi leiras-2019b.pdf. Acesso em: 14-10-2019b. ABNT- Associação Brasileira de Normas Técnicas.

ABNT-NBR - Associação Brasileira de Normas Técnicas 9393:2015: Adesivos de fusão - Determinação da viscosidade - Método do viscosímetro de Brookfield. 4 p., 2015.

ASTM - American Society for testing and materials D523-14 Standard Test Method For Specular Gloss. 10p. 2014.

CODEMIG - Companhia de Desenvolvimento Econômico de Minas Gerais. Portal da Geologia, Mapeamento Geológico, Folha de Ataléia. Disp. em: http://www.portalgeologia. com.br/index.php/mapa/\#col-form-download-tab. Acesso em 25-01-2019.

GOULDING, T.M. Epoxy Resin Adhesives. Handbook of adhesive technology.2nd ed. New York: CRC Pres, 2003, p. 116.

ISO - Organização Internacional para padronização. ISO 2555:2018: Plásticos - Resinas no estado líquido ou emulsões ou dispersões - Determinação da viscosidade aparente usando um método de viscosímetro rotacional do tipo cilindro único. 3 ed.,17 p., 2018.

NETTO, C. Projeto Leste, Minas Gerais: Cadastramento de Recursos Minerais. Belo Horizonte: CPRM/COMIG/ SEME.200 p., 1998.

SILVA, A.F. Análise Geofísica do potencial pegmatítico na região de Ataleia. Ouro Preto, 2017. 66 p. Monografia N. 255 (Conclusão de Curso), Escola de Minas Departamento de Geologia - Universidade Federal de Ouro Preto.

Submetido em 4 de março de 2020 Aceito para publicação em 11 de agosto de 2020 